\title{
Measurement Instruments for the Anthropomorphism, Animacy, Likeability, Perceived Intelligence, and Perceived Safety of Robots
}

\author{
Christoph Bartneck • Dana Kulić · Elizabeth Croft • \\ Susana Zoghbi
}

Accepted: 28 October 2008 / Published online: 20 November 2008

(C) The Author(s) 2008. This article is published with open access at Springerlink.com

\begin{abstract}
This study emphasizes the need for standardized measurement tools for human robot interaction (HRI). If we are to make progress in this field then we must be able to compare the results from different studies. A literature review has been performed on the measurements of five key concepts in HRI: anthropomorphism, animacy, likeability, perceived intelligence, and perceived safety. The results have been distilled into five consistent questionnaires using semantic differential scales. We report reliability and validity indicators based on several empirical studies that used these questionnaires. It is our hope that these questionnaires can be used by robot developers to monitor their progress. Psychologists are invited to further develop the questionnaires by adding new concepts, and to conduct further validations where it appears necessary.
\end{abstract}

\author{
C. Bartneck $(\bowtie)$ \\ Department of Industrial Design, Eindhoven University of \\ Technology, Den Dolech 2, 5600 Eindhoven, The Netherlands \\ e-mail: c.bartneck@tue.nl \\ D. Kulić \\ Nakamura \& Yamane Lab, Department of Mechano-Informatics, \\ University of Tokyo, 7-3-1 Hongo, Bunkyo-ku, Tokyo 113-8656, \\ Japan \\ e-mail: dana@ynl.t.u-tokyo.ac.jp \\ E. Croft $\cdot$ S. Zoghbi \\ Department of Mechanical Engineering, University of British \\ Columbia, 6250 Applied Science Lane, Room 2054, Vancouver, \\ V6T 1Z4, Canada \\ E. Croft \\ e-mail: ecroft@mech.ubc.ca \\ S. Zoghbi \\ e-mail: szoghbi@mech.ubc.ca
}

Keywords Human factors · Robot · Perception · Measurement

\section{Introduction}

The success of service robots and, in particular, of entertainment robots cannot be assessed only by performance criteria typically found for industrial robots. The number of processed pieces and their accordance with quality standards are not necessarily the prime objectives for an entertainment robot such as Aibo [1], or a communication platform such as iCat [2]. The performance criteria of service robots lie within the satisfaction of their users. Therefore, it is necessary to measure the users' perception of service robots, since these can not be measured within the robots themselves.

Measuring human perception and cognition has its own pitfalls, and psychologists have developed extensive methodologies and statistical tests to objectify the acquired data. Most engineers who develop robots are often unaware of this large body of knowledge, and sometimes run naïve experiments in order to verify their designs. But the same naivety can also be expected of psychologists when confronted with the task of building a robot. Human-Robot Interaction (HRI) is a multidisciplinary field, but it can not be expected that everyone masters all skills equally well. We do not intend to investigate the structure of the HRI community and the problems it is facing in the cooperation of its members. The interested reader may consult Bartneck and Rauterberg [3] who reflected on the structure of the Human-Computer Interaction community. This may also apply to the HRI community. This study is intended for the technical developers of interactive robots who want to evaluate their creations without having to take a degree in experimental psychology. 
However, it is advisable to at least consult with a psychologist over the overall methodology of the experiment.

A typical pitfall in the measurement of psychological concepts is to break them down into smaller, presumably better-known, components. This is common practice, and we do not intend to single out a particular author, but we still feel the need to present an example. Kiesler and Goetz [4] divided the concept of anthropomorphism into the sub components sociability, intellect, and personality. They measured each concept with the help of a questionnaire. This breaking down into sub components makes sense if the relationship and relative importance of the sub components are known and can therefore be calculated back into the original concept. Otherwise, a presumably vague concept is simply replaced by series of just as vague concepts. There is no reason to believe that it would be easier for the users of robots to evaluate their sociability rather than their anthropomorphism. Caution is therefore necessary so as not to overdecompose concepts. Still, it is good practice to at least decompose the concept under investigation into several items ${ }^{1}$ so as to have richer and more reliable data as was suggested by Fink, Vol. 8, p. 20 [5].

A much more reliable and possibly objective method for measuring the users' perception and cognition is to observe their behavior [6]. If, for example, the intention of a certain robot is to play a game with the user, then the fun experienced can be deduced from the time the user spends playing it. The longer the user plays, the more fun it is. However, not all internal states of a user manifest themselves in observable behavior. From a practical point of view it can also be very laborious to score the users' behaviors on the basis of video recordings.

Physiological measurements form a second group of measurement tools. Skin conductivity, heart rate, and heart variance are three popular measurements that provide a good indication of the user's arousal in real time. The measurement can be taken during the interaction with the robot. Unfortunately, these measurements can not distinguish the arousal that stems from anger from that which may originate from joy. To gain better insight into the user's state, these measurements can be complemented by other physiological measurements, such as the recognition of facial expression. In combination, they can provide real time data, but the effort of setting up and maintaining the equipment and software should not be underestimated.

A third measurement technique is questionnaires, which are often used to measure the users' attitudes. While this method is rather quick to conduct, its conceptual pitfalls are often underestimated. One of its prime limitations is, of course, that the questionnaire can be administered only after

\footnotetext{
${ }^{1}$ In the social sciences the term "item" refers to a single question or response.
}

the actual experience. Subjects have to reflect on their experience afterwards, which might bias their response. They could, for example, adapt their response to the socially acceptable response.

The development of a validated questionnaire involves a considerable amount of work, and extensive guidelines are available to help with the process [5, 7]. Development will typically begin with a large number of items, which are intended to cover the different facets of the theoretical construct to be measured; next, empirical data is collected from a sample of the population to which the measurement is to be applied. After appropriate analysis of this data, a subset of the original list of items is then selected and becomes the actual multi-indicator measurement. This measurement will then be formally assessed with regard to its reliability, dimensionality, and validity.

Due to their naivety and the amount of work necessary to create a validated questionnaire, developers of robots have a tendency to quickly cook up their own questionnaires. This conduct results in two main problems. Firstly, the validity and reliability of these questionnaires has often not been evaluated. An engineer is unlikely to trust a voltmeter developed by a psychologist unless its proper function has been shown. In the same manner, psychologists will have little trust in the results from a questionnaire developed by an engineer unless information about its validity and reliability is available. Despite the fact that we may trust experts in the field, at some point each instruments needs to be tested. Secondly, the absence of standard questionnaires makes it difficult to compare the results from different researchers. If we are to make progress in the field of human-robot interaction then we shall have to develop standardized measurement tools similar to the ITC-SOPI questionnaire that was developed to measure presence [8]. The need for standardized measurements has been acknowledged and a workshop on this topic has been conducted at the HRI2008 conference in Amsterdam.

This study attempts to make a start in the development of standardized measurement tools for human-robot interaction by first presenting a literature review on existing questionnaires, and then presenting empirical studies that give an indication of the validity and reliability of these new questionnaires. This study will take the often-used concepts of anthropomorphism, animacy, likeability, and perceived intelligence and perceived safety as starting points to propose a consistent set of five questionnaires for these concepts.

We can not offer an exhaustive framework for the perception of robots similar to the frameworks that have already been developed for social robots [9-11] that would justify the selection of these five concepts. We can only recognize that the concepts proposed have been necessary for our own research and that they are likely to have relationships with each other. A highly anthropomorphic and intelligent robot 
is likely to be perceived to be more animate and possibly also more likeable. The verification of such a model does require appropriate measurement instruments. The discussion of whether it is good practice to first develop a theory and then the observation method or vice versa has not reached a conclusion [12], but every journey begins with a first step. The proposed set of questionnaires can later be extended to cover other relevant concepts, and their relationships can be further explored. The emphasis is on presenting questionnaires that can be used directly in the development of interactive robots. Many robots are being built right now, and the engineers cannot wait for a mature model to emerge. We even seriously consider the position that such a framework can be created only once we have the robots and measurement tools in place.

Unfortunately, the literature review revealed questionnaires that used different types of items, namely Likertscales [13] and semantic differential scales [14]. If more than one questionnaire is to be used for the evaluation of a certain robot, it is beneficial if the questionnaires use the same type of items. This consistency makes it easy for the participants to learn the method and thereby avoids errors in their responses. It was therefore decided to transfer Likert type scales to semantic differential scales. We shall now discuss briefly the differences between these two types of items.

In semantic differential scales the respondent is asked to indicate his or her position on a scale between two bipolar words, the anchors (see Fig. 1, top). In Likert scales (see Fig. 1, bottom), subjects are asked to respond to a stem, often in the form of a statement, such as "I like ice cream". The scale is frequently anchored with choices of "agree""disagree" or "like"-“dislike".

Both are rating scales, and provided that response distributions are not forced, semantic differential data can be treated just as any other rating data [7]. The statistical analysis is identical. However, a semantic differential format may effectively reduce acquiescence bias without lowering psychometric quality [15]. A common objection to Osgood's semantic differential method is that it appears to assume that the adjectives chosen as anchors mean the same to everyone. Thus, the method becomes self-contradictory; it starts from the presumption that different people interpret the same word differently, but has to rely on the assumption that this is not true for the anchors. However, this study proposes to use the semantic differential scales to evaluate

\section{$\begin{array}{llllllll}\text { Strong } & 1 & 2 & 3 & 4 & 5 & \text { Weak }\end{array}$}

\begin{tabular}{|lllllllll}
\hline I like ice cream & Disagree & 1 & 2 & 3 & 4 & 5 & Agree \\
\hline
\end{tabular}

Fig. 1 Example of a semantic differential scale (top) and L. Likert scale (bottom). The participant would be asked to rate the stimulus on this scale by circling one of the numbers not the meaning of words, but the attitude towards robots. Powers and Kiesler [16] report a negative correlation (-.23) between "Human-likeness" and "Machine-likeness", which strengthens our view that semantic differentials are a useful tool for measuring the users' perception of robots, while we remain aware of the fact that every method has its limitations.

Some information on the validity and reliability of the questionnaires is already available from the original studies on which they are based. However, the transformation from Likert scales to semantic differential scales may compromise these indicators to a certain degree. We shall compensate this possible loss by reporting on complementary empirical studies later in the text. First, we would like to discuss the different types of validity and reliability.

Fink in Vol. 8, pp. 5-44, [5] discusses several forms of reliability and validity. Among the scientific forms of validity we find content validity, criterion validity, and construct validity. The latter, which determines the degree to which the instrument works in comparison with others, can only be assessed after years of experience with a questionnaire, and construct validity is often not calculated as a quantifiable statistic. Given the short history of research in HRI it would appear difficult to achieve construct validity. The same holds true for criterion validity. There is a scarcity of validated questionnaires with which our proposed questionnaires can be compared. We can make an argument for content validity since experts in the field carried out the original studies, and measurements of the validity and reliability have even been published from time to time. The researchers involved in the transformation of the proposed questionnaires were also in close contact with relevant experts in the field with regard to the questionnaires. The proposed questionnaires can therefore be considered to have content validity.

It is easier to evaluate the reliability of the questionnaire, and Fink describes three forms: test-retest reliability, alternate form reliability, and internal consistency reliability. The latter is a measurement for how well the different items measure the same concept, and it is of particular importance to the questionnaires proposed because they are designed to be homogenous in content. Internal consistency involves the calculation of a statistic known as Cronbach's Alpha. It measures the internal consistency reliability among a group of items that are combined to form a single scale. It reflects the homogeneity of the scale. Given the choice of homogeneous semantic differential scales, alternate form reliability appears difficult to achieve. The items cannot simply be negated and asked again because semantic differential scales already include dichotomous pairs of adjectives. Test-retest reliability can even be tested within the same experiment by splitting the participants randomly into two groups. This procedure requires a sufficiently large number of participants and unfortunately none of the studies that we have 
access to have had enough participants to allow for a meaningful test-retest analysis. For both, test-retest reliability and internal consistency reliability, Nunnally [17] recommends a minimum value of 0.7 . We would now like to discuss the five concepts of anthropomorphism, animacy, likeability, perceived intelligence, and perceived safety in more detail, and describe a questionnaire for each of them.

\section{Anthropomorphism}

Anthropomorphism refers to the attribution of a human form, human characteristics, or human behavior to nonhuman things such as robots, computers, and animals. Hiroshi Ishiguro, for example, develops androids that, for a short period, are indistinguishable from human beings [18]. His highly anthropomorphic androids struggle with the so-called 'uncanny valley', a theory that states that as a robot is made more humanlike in its appearance and movements, the emotional response from a human being to the robot becomes increasingly positive and empathic, until a point is reached beyond which the response quickly becomes that of intense repulsion. However, as the appearance and movements continue to become less distinguishable from those of a human being, the emotional response becomes positive once more and approaches human-human empathy levels.

Even if it is not the intention of the design of a certain robot to be as humanlike as possible, it still remains important to match the appearance of the robot with its abilities. A too anthropomorphic appearance can evoke expectations that the robot might not be able to fulfill. If, for example, the robot has a human-shaped face then the naïve user will expect that the robot is able to listen and to talk. To prevent disappointment it is necessary for all developers to pay close attention to the anthropomorphism level of their robots.

An interesting behavioral measurement for anthropomorphism has been presented by Minato et al. [19]. They attempted to analyze differences in where the participants were looking when they looked at either a human or an android. The hypothesis is that people look differently at humans compared to robots. They have not been able to produce reliable conclusions yet, but their approach could turn out to be very useful, assuming that they can overcome the technical difficulties.

MacDorman [20] presents an example of a naïve questionnaire. A single question is asked to assess the humanlikeness of what is being viewed (9-point semantic differential, mechanical versus humanlike). It is good practice in the social sciences to ask multiple questions about the same concept in order to be able to check the participants' consistency and the questionnaire's reliability. Powers and Kiesler [16], in comparison, used six items and are able to report a Cronbach's Alpha of 0.85 . Their questionnaire therefore appears to be more suitable. It was necessary to transform the items used by Powers and Kiesler into semantic differentials: Fake/Natural, Machinelike/Humanlike, Unconscious/Conscious, Artificial/Lifelike, and Moving rigidly/Moving elegantly.

Two studies are available in which this new anthropomorphism questionnaire was used. The first one reports a Cronbach's Alpha of 0.878 [21] and we would like to report the Cronbach's Alphas for the second study [22] in this paper. The study consisted of three within conditions for which the Cronbach's Alphas must be reported separately. We can report a Cronbach's Alpha of 0.929 for the human condition, 0.923 for the android condition and 0.856 for the masked android condition. The alpha values are well above 0.7 , so we can conclude that the anthropomorphism questionnaire has sufficient internal consistency reliability.

\section{Animacy}

The goal of many robotics researchers is to make their robots lifelike. Computer games, such as The Sims, Creatures, or Nintendo Dogs show that lifelike creatures can deeply involve users emotionally. This involvement can then be used to influence users [23]. Since Heider and Simmel [24], a considerable amount of research has been devoted to the perceived animacy and "intentions" of geometric shapes on computer screens. Scholl and Tremoulet [25] offer a good summary of the research field, but, on examining the list of references, it becomes apparent that only two of the 79 references deal directly with animacy. Most of the reviewed work focuses on causality and intention. This may indicate that the measurement of animacy is difficult.

The classic perception of life, which is often referred to as animacy, is based on the Piagetian framework centred on "moving of one's own accord". Observing children in the world of "traditional" - that is, non-computationalobjects, Piaget found that at first they considered everything that moved to be alive, but later, only things that moved without an external push or pull. Gradually, children refined the notion to mean "life motions," namely only those things that breathed and grew were taken to be alive. This framework has been widely used, and even the study of artificial life has been considered as an opportunity to extend his original framework [26]. Piaget's framework emphasizes the importance of movement and intentional behaviour for the perception of animacy.

This framework is supported by the observation that abstract geometrical shapes that move on a computer screen are already being perceived as being alive [25], especially if they change their trajectory nonlinearly or if they seem to interact with their environments, for example, by avoiding obstacles or seeking goals [27]. Being alive is one of the 
major criteria that distinguish human beings from machines, but since robots exhibit movement and intentional behaviour, it is not obvious how human beings perceive them. The category of "sort of alive" becomes increasingly used [28]. This gradient of "alive" is reflected by the recently proposed psychological benchmarks of autonomy, imitation, intrinsic moral value, moral accountability, privacy, and reciprocity that in the future may help to deal with the question of what constitutes the essential features of being human in comparison with being a robot [29].

First discussions on a robot's moral accountability have already started [30], and an analogy between animal rights and android science has been discussed [31]. Other benchmarks for life, such as the ability to reproduce, have been challenged by the first attempts at robotic self-reproduction [32].

Returning to the discussion of how to measure animacy, we observe that Tremoulet and Feldman [33] only asked their participants to evaluate the animacy of 'particles' under a microscope on a single scale (7-point Likert scale, $1=$ definitely not alive, $7=$ definitely alive). It is questionable how much sense it makes to ask participants about the animacy of particles. By definition they cannot be alive since particles tend to be even smaller than the simplest organisms.

Asking about the perceived animacy of a certain stimulus makes sense only if there is a possibility for it to be alive. Robots can show physical behavior, reactions to stimuli, and even language skills. These are typically attributed only to animals, and hence it can be argued that it makes sense to ask participants about their perception of the animacy of robots.

McAleer et al. [34] claim to have analyzed the perceived animacy of modern dancers and their abstractions on a computer screen, but only qualitative data of the perceived arousal is presented. Animacy was measured with free responses. They looked for terms and statements that indicated that subjects had attributed human movements and characteristics to the shapes. These were terms such as "touched", "chased", and "followed", and emotions such as "happy" or "angry". Other guides to animacy were when the shapes were generally being described in active roles, as opposed to being controlled in a passive role. However, they do not present any quantitative data for their analysis.

A better approach has been presented by Lee, Kwan Min, Park, Namkee and Song, Hayeon [35]. With their four items (10-point Likert scale; lifelike, machine-like, interactive, and responsive) they have been able to achieve a Cronbach's Alpha of 0.76. For the questionnaires in this study, their items have been transformed into semantic differentials: Dead/Alive, Stagnant/Lively, Mechanical/Organic, Artificial/Lifelike, Inert/Interactive, Apathetic/Responsive. One study used this new questionnaire [36] and reported a Cronbach's Alpha of 0.702 , which is sufficiently high for us to conclude that the new animacy questionnaire has sufficient internal consistency reliability.

\section{Likeability}

It has been reported that the way in which people form positive impressions of others is to some degree dependent on the visual and vocal behavior of the targets [37], and that positive first impressions (e.g., likeability) of a person often lead to more positive evaluations of that person [38]. Interviewers report knowing within 1 to 2 minutes whether a potential job applicant is a winner, and people report knowing within the first 30 seconds the likelihood that a blind date will be a success [39]. There is a growing body of research indicating that people often make important judgments within seconds of meeting a person, sometimes remaining quite unaware of both the obvious and subtle cues that may be influencing their judgments. Since computers, and thereby robots in particular, are to some degree treated as social actors [40], it can be assumed that people are able to judge robots in a similar way.

Jennifer Monahan [41] complemented her "liking" question with 5-point semantic differential scales: nice/awful, friendly/unfriendly, kind/unkind, and pleasant/unpleasant, because these judgments tend to demonstrate considerable variance in common with "liking" judgments [42]. Monahan later eliminated the kind-unkind and pleasant-unpleasant items in her own analysis since they did not load sufficiently in a factor analysis that also included items from three other factors. The Cronbach's Alpha of 0.68 therefore relates only to this reduced scale. Her experimental focus is different from the intended use of her questionnaire in the field of HRI. She also included concepts of physical attraction, conversational skills, and other orientations, which might become an element of the questionnaire series at a later stage. In particular, physical attraction might require additional conceptual and social consideration, since it may also entail sexuality. No reports on successful human-robot reproduction are available yet and hopefully never will be. We decided to only include the five items, since it is always possible to exclude items in cases where they would not contribute to the reliability and validity of the questionnaire.

Two studies used this new likeability questionnaire. The first reports a Cronbach's Alpha of 0.865 [21], and we report the Cronbach's Alpha for the second [22] in this paper. The study consisted of three "within" conditions for which the Cronbach's Alpha must be reported separately. Without going into too much detail of the study, we can report a Cronbach's Alpha of 0.923 for the human condition, 0.878 for the android condition, and 0.842 for the masked android condition. The alpha values are well above 0.7 , and hence we can conclude that the likeability questionnaire has sufficient internal consistency reliability. 


\section{Perceived Intelligence}

Interactive robots face a tremendous challenge in acting intelligently. The reasons can be traced back to the field of artificial intelligence (AI). The robots' behaviors are based on methods and knowledge that were developed by AI. Many of the past promises of AI have not been fulfilled, and AI has been criticized extensively [43-46].

One of the main problems that $\mathrm{AI}$ is struggling with is the difficulty of formalizing human behavior, for example, in expert systems. Computers require this formalization to generate intelligent and human-like behavior. And as long as the field of AI has not made considerable progress on these issues, robot intelligence will remain at a very limited level. So far, we have been using many Wizard-of-Oz methods to fake intelligent robotic behavior, but this is possible only in the confines of the research environment. Once the robots are deployed in the complex world of everyday users, their limitations will become apparent. Moreover, when the users are interacting with the robot for years rather than minutes, they will become aware of the limited abilities of most robots.

Evasion strategies have also been utilized. The robot would show more or less random behavior while interacting with the user, and the user in turn sees patterns in this behavior which he/she interprets as intelligence. Such a strategy will not lead to a solution of the problem, and its success is limited to short interactions. Given sufficient time the user will give up his/her hypothesized patterns of the robot's intelligent behavior and become bored with its limited random vocabulary of behaviors. In the end, the perceived intelligence of a robot will depend on its competence [47]. To monitor the progress being made in robotic intelligence it is important to have a good measurement tool.

Warner and Sugarman [48] developed an intellectual evaluation scale that consists of five seven-point semantic differential items: Incompetent/Competent, Ignorant/ Knowledgeable, Irresponsible/Responsible, Unintelligent/ Intelligent, Foolish/Sensible. Parise et al. [49] excluded one question from this scale, and reported a Cronbach's Alpha of 0.92 . The questionnaire was again used by Kiesler, Sproull and Waters [50], but no alpha was reported. Three other studies used the perceived intelligence questionnaire, and reported Cronbach's Alpha values of 0.75 [22], 0.769 [51], and 0.763 [36]. These values are above the suggested 0.7 threshold, and hence the perceived intelligence questionnaire can be considered to have satisfactory internal consistency reliability.

\section{Perceived Safety}

A key issue for robots interacting with humans is safety. The issue has received considerable attention in the robotics lit- erature, both in systems and standards established for industrial robots and for service robots intended for use in the home. The proposed approaches can be classified into three broad categories: (i) reduce the hazard through mechanical redesign, (ii) control the hazard through electronic or physical safeguards, and, (iii) warn the operator/user, either during operation or through training [52]. Examples of mechanical redesign include using a whole-body robot visco-elastic covering [53, 54], the use of spherical and compliant joints [54-56], and distributed parallel actuation mechanisms to lower the effective inertia of the robot near the end effector $[57,58]$. Control approaches have included impact force control and passive control [59-61], as well as control strategies based on either discrete [54, 62] or continuous safeguarding zones [63, 64]. Recent work has also focused on measurement and analysis of forces and injury during human robot collisions [65]. However the focus of these works is on safety based on the robot's perception, they do not consider the human's perception of safety during the interaction. Perceived safety describes the user's perception of the level of danger when interacting with a robot, and the user's level of comfort during the interaction. Achieving a positive perception of safety is a key requirement if robots are to be accepted as partners and co-workers in human environments. Perceived safety and user comfort have rarely been measured directly. Instead, indirect measures have been usedthe measurement of the affective state of the user through the use of physiological sensors [66-68], questionnaires $[66,69,70]$, and direct input devices [71]. That is, instead of asking subjects to evaluate the robot, researchers frequently use affective state estimation or questionnaires asking how the subject feels in order to measure the perceived safety and comfort level indirectly.

For example, Sarkar proposes the use of multiple physiological signals to estimate affective state, and to use this estimate to modify robotic actions to make the user more comfortable [72]. Rani et al. [67, 68] use heart-rate analysis and multiple physiological signals to estimate human stress levels. In Rani et al. [67], an autonomous mobile robot monitors the stress level of the user, and if the level exceeds a certain value, the robot returns to the user in a simulated rescue attempt. However, in their study, the robot does not interact directly with the human; instead, pre-recorded physiological information is used to allow the robot to assess the human's condition.

Koay et al. [72] describe an early study where human reaction to robot motions was measured online. In this study, 28 subjects interacted with a robot in a simulated living room environment. The robot motion was controlled by the experimenters in a "Wizard of Oz" setup. The subjects were asked to indicate their level of comfort with the robot by means of a handheld device. The device consisted of a single slider control to indicate comfort level, and a radio signal 
data link. Data from only 7 subjects was considered reliable, and was included in subsequent analysis. Analysis of the device data with the video of the experiment found that subjects indicated discomfort when the robot was blocking their path, the robot was moving behind them, or the robot was on a collision course with them.

Nonaka et al. [73] describe a set of experiments where human response to pick-and-place motions of a virtual humanoid robot is evaluated. In their experiment, a virtual reality display is used to depict the robot. Human response is measured through heart rate measurements and subjective responses. A 6-level scale is used from $1=$ "never" to $6=$ "very much", for the categories of "surprise", "fear", "disgust", and "unpleasantness". No relationship was found between the heart rate and robot motion, but a correlation was reported between the robot velocity and the subject's rating of "fear" and "surprise". In a subsequent study [69], a physical mobile manipulator was used to validate the results obtained with the virtual robot. In this case, subjects are asked to rate their responses on the following (5-point) direction levels: "secure-anxious", "restless-calm", "comfortable-unpleasant", "unapproachable-accessible", "favorable-unfavorable", "tense-relaxed", "unfriendlyfriendly", "interesting-tedious", and "unreliable-reliable". They are also asked to rate their level of "intimidated" and "surprised" on a 5-point Likert scale. The study finds that similar results are obtained regardless of whether a physical or a virtual robot is used. Unfortunately, no information about the reliability or validity of their scales is available.

There is a very large number of different questions that can be asked on the topic of safety and comfort in response to physical robot motion. This underlines the need for a careful and studied set of baseline questions for eliciting comparable results from research efforts, especially in concert with physiological measurement tools. It becomes apparent that two approaches can be taken to assess the perceived safety. On the one hand the users can be asked to evaluate their impression of the robot, and on the other hand they can be asked to assess their own affective state. It is assumed that if the robot is perceived to be dangerous then the user affective state would be tense.

Kulic and Croft $[66,74]$ combined a questionnaire with physiological sensors to estimate the user's level of anxiety and surprise during sample interactions with an industrial robot. They ask the user to rate their level of anxiety, surprise, and calmness during each sample robot motion. A 5 point Likert scale is used. The Cronbach's Alpha for the affective state portion of the questionnaire is 0.91 . In addition, the subject is asked to rate their level of attention during the robot motion, to ensure that the elicited affective state was caused by the robot rather than by some other internal or external distraction. In their work, the effect of robot movement on the human response, both in terms of safety and trajectory employed, is examined. They show that motion planning can be used to reduce the perceived anxiety and surprise felt by subjects during high speed movements. This and later work $[75,76]$ by the same authors showed a strong statistical correlation between the affective state reported by the subjects and their physiological responses.

The scales they produced were then transformed to the following semantic differential scales: Anxious/Relaxed, Agitated/Calm, Quiescent/Surprised. This revised questionnaire was utilized with a new set of 16 subjects (10 males and 6 females) using the same robot and physiological sensor system and the same experimental protocol as in the previous study [74]. In the experiment, the user is shown a robot manipulator performing various motions and asked to rate their responses to the robot behavior. The robot performs two different tasks, a pick and place task and a reach and retract task. These tasks were chosen to represent typical motions a robot could be asked to perform during human-robot interaction. Two planning strategies were used to plan the path of the robot for each task, a safe planning strategy [77] and the nominal potential field approach [78]. Each motion was presented at three different speeds, with the fastest being the maximum velocity of the robot, for a total of 12 trajectories. The trajectories were presented to each subject in random order.

Table 1 shows the correlation analysis between the new measuring scales and speed. In correspondence with previous results, strong correlation coefficients were obtained between speed and reported levels of Anxiety, Agitation and Surprise. All correlation coefficients were significant at the 0.01 level for 2-tailed t-tests.

Table 2 presents a 3 -factor ANOVA table for the reported levels of Anxiety/Relaxation. There was a significant effect of all factors — speed, task, and type of planning strategy —at the 0.05 level while all interactions were not significant.

Utilizing this semantic differential scaled questionnaire yielded the same statistical outcomes as the previous

Table 1 Correlation analysis

\begin{tabular}{lrlll}
\hline & Speed & Anxious/Relaxed & Agitated/Calm & Quiescent/Surprised \\
\hline Speed & \multicolumn{1}{c}{1} & & & \\
Anxious/Relaxed & -0.530 & 1 & & \\
Agitated/Calm & -0.553 & 0.842 & 1 & \\
Quiescent/Surprised & 0.695 & -0.711 & -0.732 & 1 \\
\hline
\end{tabular}


Table 2 ANOVA table for Anxiety/Relaxation

\begin{tabular}{lrccc}
\hline Source of variation & $d f$ & \multicolumn{1}{l}{$M S$} & \multicolumn{1}{l}{$F$} & \multicolumn{1}{l}{$p$} \\
\hline Speed & 2 & 42.09 & 40.96 & .000 \\
Task & 1 & 5.56 & 5.41 & .021 \\
Planning strategy & 1 & 7.33 & 7.13 & .008 \\
Speed $*$ Task & 2 & .001 & .001 & .999 \\
Speed $*$ Planner & 2 & .25 & .25 & .783 \\
Task $*$ Planner & 1 & 1.44 & 1.40 & .238 \\
Speed $*$ Task $*$ Planner & 2 & .15 & .15 & .863 \\
Error & 181 & 1.03 & & \\
\hline
\end{tabular}

5-point Likert scale questionnaire for Anxiety, Surprise and Calmness. The results previously obtained do have considerable relevance to the results of the new semantic differential questionnaire. The correlation of the previous questionnaire with the physiological measurements suggest a strong validity of that Likert-style questionnaire. Given the similar results for the semantic differential version of the questionnaire, it is highly likely that the correlation to the physiological measurements still exists, and hence the validity of the questionnaire may be assumed. These results show that also the new semantic differential questionnaire can provide a repeatable and reliable measure for assessing user's perceived safety in response to robot motion.

\section{Conclusions}

The study proposes a series of questionnaires to measure the users' perception of robots. This series will be called "Godspeed" because it is intended to help creators of robots on their development journey. Appendix shows the application of the five Godspeed questionnaires using 5-point scales. It is important to notice that there is a certain overlap between anthropomorphism and animacy. The item artificial/lifelike appears in both sections. This is to be expected, since being alive is an essential part of being human-like. An additional correlation analysis is therefore recommended when both questionnaires are being administered in the same study. We also have to point out that the sensitivity of the Godspeed questionnaire series is not completely known. There may very well be a small difference in perception between two almost identical robots, but this difference might be too small to be picked up by the questionnaire with a small number of participants. If the experimenter suspects such a situation, then we recommend increasing the number of participants, based on a power analysis.

When one of these questionnaires is used by itself in a study it would be useful to mask the questionnaire's intention by adding dummy items, such as optimistic/pessimistic. If multiple questionnaires are used then the items should be mixed so as to mask the intention. Of course, each semantic differential needs to be headed with an instruction, such as "Please rate your impression of the robot". The interested reader may consult [5] to learn more about designing questionnaires. Before calculating the mean scores for anthropomorphism, animacy, likeability, or perceived intelligence it is good practice to perform a reliability test and report the resulting Cronbach's Alpha.

The interpretation of the results has, of course, some limitations. First, it is extremely difficult to determine the ground truth. In other words, it is complicated to determine objectively, for example, how anthropomorphic a certain robot is. Many factors, such as the cultural backgrounds of the participants, prior experiences with robots, and personality may influence the measurements. Taking all the possible biases into account would require a complex and therefore impracticable experiment. The resulting values of the measurements should therefore be interpreted not as absolute values, but rather as a tool for comparison. Robot developers can, for example, use the questionnaires to compare different configurations of a robot. The results may then help the developers to choose one option over the other. In the future, this set of questionnaires could be extended to also include the believability of a robot, the enjoyment of interacting with it, and the robot's social presence. However, we have to point out that the perceptions of humans is not stable. The more humans gets used to the presence of robots, the more their knowledge and expectations might change. The questionnaires can therefore only offer a snapshot and it is likely that the if the experiment would be repeated in twenty years, it would yield different results.

It is the hope of the authors that robot developers may find this collection of measurement tools useful. Using these tools would make the results in HRI research more comparable and could therefore increase our progress. Interested readers, in particular experimental psychologists, are invited to continue to develop these questionnaires, and to validate them further.

A necessary development would be translation into different languages. Only native speakers can understand the true meanings of the adjectives in their language. It is therefore necessary to translate the questionnaires into the mother language of the participants. Appendix includes the Japanese translation of the adjectives that we created using the back translation method. It is advisable to use the same method to translate the questionnaire into other languages. It would be appreciated if other translations are reported back to the authors of this study. They will then be collected and posted on this website: http://www.bartneck.de/2008/03/11/the-godspeedquestionnaire-series/.

Acknowledgement The Intelligent Robotics and Communication Laboratories at the Advanced Telecommunications Institute International (Kyoto, Japan) supported this study. 
Open Access This article is distributed under the terms of the Creative Commons Attribution Noncommercial License which permits any noncommercial use, distribution, and reproduction in any medium, provided the original author(s) and source are credited.

\section{Appendix}

\section{GODSPEED I: ANTHROPOMORPHISM}

Please rate your impression of the robot on these scales:

$$
\begin{array}{rllllll}
\text { 以下のスケールに基づいてこのロボットの印象を評価してください。 } \\
\text { Fake 偽物のような } & 1 & 2 & 3 & 4 & 5 & \text { Natural 自然な } \\
\text { Machinelike 機械的 } & 1 & 2 & 3 & 4 & 5 & \text { Humanlike 人間的 } \\
\text { Unconscious 意識を持たない } & 1 & 2 & 3 & 4 & 5 & \text { Conscious 意識を持っている } \\
\text { Artificial 人工的 } & 1 & 2 & 3 & 4 & 5 & \text { Lifelike 生物的 } \\
\text { Moving rigidly ぎこちない動き } & 1 & 2 & 3 & 4 & 5 & \text { Moving elegantly洗練された動き }
\end{array}
$$

GODSPEED II: ANIMACY

Please rate your impression of the robot on these scales:

$\begin{array}{rllllll}\text { 以下のスケールに基づいてこのロボットの印象を評価してください。 } \\ \text { Dead 死んでいる } & 1 & 2 & 3 & 4 & 5 & \text { Alive 生きている } \\ \text { Stagnant 活気のない } & 1 & 2 & 3 & 4 & 5 & \text { Lively 生き生きとした } \\ \text { Mechanical 機械的な } & 1 & 2 & 3 & 4 & 5 & \text { Organic 有機的な } \\ \text { Artificial 人工的な } & 1 & 2 & 3 & 4 & 5 & \text { Lifelike 生物的な } \\ \text { Inert 不活発な } & 1 & 2 & 3 & 4 & 5 & \text { Interactive 対話的な } \\ \text { Apathetic 無関心な } & 1 & 2 & 3 & 4 & 5 & \text { Responsive 反応のある }\end{array}$

\section{GODSPEED III: LIKEABILITY}

Please rate your impression of the robot on these scales:

$\begin{array}{rllllll}\text { 以下のスケールに基づいてこのロボットの印象を評価してください。 } \\ \text { Dislike 嫌い } & 1 & 2 & 3 & 4 & 5 & \text { Like 好き } \\ \text { Unfriendly 親しみにくい } & 1 & 2 & 3 & 4 & 5 & \text { Friendly 親しみやすい } \\ \text { Unkind 不親切な } & 1 & 2 & 3 & 4 & 5 & \text { Kind 親切な } \\ \text { Unpleasant 不愉快な } & 1 & 2 & 3 & 4 & 5 & \text { Pleasant 愉快な } \\ \text { Awful ひどい } & 1 & 2 & 3 & 4 & 5 & \text { Nice 良い }\end{array}$

\section{GODSPEED IV: PERCEIVED INTELLIGENCE}

Please rate your impression of the robot on these scales:

$\begin{array}{rllllll}\text { 以下のスケールに基づいてこのロボットの印象を評価してください。 } \\ \text { Incompetent 無能な } & 1 & 2 & 3 & 4 & 5 & \text { Competent 有能な } \\ \text { Ignorant 無知な } & 1 & 2 & 3 & 4 & 5 & \text { Knowledgeable 物知りな } \\ \text { Irresponsible 無責任な } & 1 & 2 & 3 & 4 & 5 & \text { Responsible 責任のある } \\ \text { Unintelligent 知的でない, } & 1 & 2 & 3 & 4 & 5 & \text { Intelligent 知的な } \\ \text { Foolish 愚かな } & 1 & 2 & 3 & 4 & 5 & \text { Sensible 賢明な }\end{array}$

GODSPEED V: PERCEIVED SAFETY

Please rate your emotional state on these scales:

$\begin{array}{rllllll}\text { 以下のスケールに基づいてあなたの心の状態を評価してください。 } \\ \text { Anxious 不安な } & 1 & 2 & 3 & 4 & 5 & \text { Relaxed 落ち着いた } \\ \text { Agitated 動摇している } & 1 & 2 & 3 & 4 & 5 & \text { Calm 冷静な } \\ \text { Quiescent 平穏な } & 1 & 2 & 3 & 4 & 5 & \text { Surprised 驚いた }\end{array}$




\section{References}

1. Sony (1999) Aibo, vol 1999

2. Breemen A, Yan X, Meerbeek B (2005) iCat: an animated user-interface robot with personality. In: Fourth international conference on autonomous agents \& multi agent systems, Utrecht

3. Bartneck C, Rauterberg M (2007) HCI reality-an unreal tournament. Int J Hum Comput Stud 65:737-743

4. Kiesler S, Goetz J (2002) Mental models of robotic assistants. In: CHI'02 extended abstracts on Human factors in computing systems, Minneapolis, Minnesota, USA

5. Fink A (2003) The survey kit, 2nd edn. Sage, Thousand Oaks

6. Kooijmans $\mathrm{T}$, Kanda $\mathrm{T}$, Bartneck $\mathrm{C}$, Ishiguro $\mathrm{H}$, Hagita $\mathrm{N}$ (2007) Accelerating robot development through integral analysis of human-robot interaction. IEEE Trans Robot 23:1001-1012

7. Dawis RV (1987) Scale construction. J Counsel Psychol 34:481489

8. Lessiter J, Freeman J, Keogh E, Davidoff J (2001) A cross-media presence questionnaire: The itc sense of presence inventory. Presence 10:282-297

9. Fong T, Nourbakhsh I, Dautenhahn K (2003) A survey of socially interactive robots. Robot Auton Syst 42:143-166

10. Bartneck C, Forlizzi J (2004) A design-centred framework for social human-robot interaction. In: Ro-Man2004, Kurashiki, pp 591-594

11. Dautenhahn K (2007) Socially intelligent robots: dimensions of human-robot interaction. Philos Trans R Soc B Biol Sci 362:679704

12. Chalmers AF (1999) What is this thing called science? 3rd edn. Hackett, Indianapolis

13. Likert R (1932) A technique for the measurement of attitudes. Arch Psychol 140:1-55

14. Osgood CE, Suci GJ, Tannenbaum PH (1957) The measurements of meaning. University of Illinois Press, Champaign

15. Friborg O, Martinussen M, Rosenvinge JH (2006) Likert-based vs. semantic differential-based scorings of positive psychological constructs: A psychometric comparison of two versions of a scale measuring resilience. Pers Individ Differ 40:873-884

16. Powers A, Kiesler S (2006) The advisor robot: tracing people's mental model from a robot's physical attributes. In: 1st ACM SIGCHI/SIGART conference on Human-robot interaction, Salt Lake City, Utah, USA

17. Nunnally JC (1978) Psychometric theory, 2nd edn. McGraw-Hill, New York

18. Ishiguro H (2005) Android Science-Towards a new crossinterdisciplinary framework. In: CogSci workshop towards social mechanisms of android science, Stresa, pp 1-6

19. Minato T, Shimada M, Itakura S, Lee K, Ishiguro H (2005) Does gaze reveal the human likeness of an android? In: 4th IEEE international conference on development and learning, Osaka

20. MacDorman KF (2006) Subjective ratings of robot video clips for human likeness, familiarity, and eeriness: An exploration of the uncanny valley. In: ICCS/CogSci-2006 long symposium: toward social mechanisms of android science, Vancouver

21. Bartneck C, Kanda T, Ishiguro H, Hagita N (2007) Is the uncanny valley an uncanny cliff? In: 16th IEEE international symposium on robot and human interactive communication, RO-MAN 2007, Jeju, Korea, pp 368-373

22. Bartneck C, Kanda T, Ishiguro H, Hagita N (2008) My robotic doppelganger-a critical look at the uncanny valley theory. In: Interaction studies-social behaviour and communication in biological and artificial systems

23. Fogg BJ (2003) Persuasive technology: using computers to change what we think and do. Morgan Kaufmann, San Mateo

24. Heider F, Simmel M (1944) An experimental study of apparent behavior. Am J Psychol 57:243-249
25. Scholl B, Tremoulet PD (2000) Perceptual causality and animacy. Trends Cogn Sci 4:299-309

26. Parisi D, Schlesinger M (2002) Artificial life and Piaget. Cogn Dev 17:1301-1321

27. Blythe P, Miller GF, Todd PM (1999) How motion reveals intention: Categorizing social interactions. In: Gigerenzer G, Todd P (eds) Simple heuristics that make us smart. Oxford University Press, London, pp 257-285

28. Turkle S (1998) Cyborg babies and cy-dough-plasm: ideas about life in the culture of simulation. In: Davis-Floyd R, Dumit J (eds) Cyborg babies: from techno-sex to techno-tots. Routledge, New York, pp 317-329

29. Kahn P, Ishiguro H, Friedman B, Kanda T (2006) What is a human?-Toward psychological benchmarks in the field of human-robot interaction. In: The 15th IEEE international symposium on robot and human interactive communication, ROMAN 2006, Salt Lake City, pp 364-371

30. Calverley DJ (2005) Toward a method for determining the legal status of a conscious machine. In: AISB 2005 symposium on next generation approaches to machine consciousness: imagination, development, intersubjectivity, and embodiment, Hatfield

31. Calverley DJ (2006) Android science and animal rights, does an analogy exist? Connect Sci 18:403-417

32. Zykov V, Mytilinaios E, Adams B, Lipson H (2005) Selfreproducing machines. Nature 435:163-164

33. Tremoulet PD, Feldman J (2000) Perception of animacy from the motion of a single object. Perception 29:943-951

34. McAleer P, Mazzarino B, Volpe G, Camurri A, Patterson H, Pollick F (2004) Perceiving animacy and arousal in transformed displays of human interaction. J Vis 4:230-230

35. Lee KM, Park N, Song H (2005) Can a robot be perceived as a developing creature? Hum Commun Res 31:538-563

36. Bartneck C, Kanda T, Mubin O, Mahmud AA (2007) The perception of animacy and intelligence based on a robot's embodiment. In: Humanoids 2007, Pittsburgh

37. Clark N, Rutter D (1985) Social categorization, visual cues and social judgments. Eur J Soc Psychol 15:105-119

38. Robbins T, DeNisi A (1994) A closer look at interpersonal affect as a distinct influence on cognitive processing in performance evaluations. J Appl Psychol 79:341-353

39. Berg JH, Piner K (1990) Social relationships and the lack of social relationship. In: Duck W, Silver RC (eds) Personal relationships and social support. Sage, Thousand Oaks, pp 104-221

40. Nass C, Reeves B (1996) The media equation. SLI Publications/Cambridge University Press, Cambridge

41. Monahan JL (1998) I don't know it but I like you-the influence of non-conscious affect on person perception. Hum Commun Res 24:480-500

42. Burgoon JK, Hale JL (1987) Validation and measurement of the fundamental themes for relational communication. Commun Monogr 54:19-41

43. Dreyfus HL, Dreyfus SE (1992) What computers still can't do: a critique of artificial reason. MIT Press, Cambridge

44. Dreyfus HL, Dreyfus SE, Athanasiou T (1986) Mind over machine: the power of human intuition and expertise in the era of the computer. Free Press, New York

45. Weizenbaum J (1976) Computer power and human reason: from judgment to calculation. Freeman, San Francisco

46. Searle JR (1980) Minds, brains and programs. Behav Brain Sci 3:417-457

47. Koda T (1996) Agents with faces: a study on the effect of personification of software agents. MIT Media Lab, Cambridge

48. Warner RM, Sugarman DB (1996) Attributes of personality based on physical appearance, speech, and handwriting. J Pers Soc Psychol 50:792-799 
49. Parise S, Kiesler S, Sproull LD, Waters K (1996) My partner is a real dog: cooperation with social agents. In: 1996 ACM conference on computer supported cooperative work, Boston, Massachusetts, United States, pp 399-408

50. Kiesler S, Sproull L, Waters K (1996) A prisoner's dilemma experiment on cooperation with people and human-like computers. J Pers Soc Psychol 70:47-65

51. Bartneck C, Verbunt M, Mubin O, Mahmud AA (2007) To kill a mockingbird robot. In: 2nd ACM/IEEE international conference on human-robot interaction, Washington DC, pp 81-87

52. American National Standards Institute (1999) RIA/ANSI R15.06-1999 American national standard for industrial robots and robot systems-safety requirements. American National Standards Institute, New York

53. Yamada Y, Hirasawa Y, Huang S, Umetani Y, Suita K (1997) Human-robot contact in the safeguarding space. In: IEEE/ASME transactions on mechatronics, vol 2, pp 230-236

54. Yamada Y, Yamamoto T, Morizono T, Umetani Y (1999) FTAbased issues on securing human safety in a human/robot coexistence system. In: IEEE international conference on systems, man, and cybernetics, 1999. IEEE SMC'99 conference proceedings, vol 2, pp 1058-1063

55. Bicchi A, Rizzini SL, Tonietti G (2001) Compliant design for intrinsic safety: general issues and preliminary design. In: 2001 IEEE/RSJ international conference on intelligent robots and systems, 2001. Proceedings, vol 4, pp 1864-1869

56. Bicchi A, Tonietti G (2004) Fast and "soft-arm" tactics [robot arm design]. IEEE Robot Autom Mag 11:22-33

57. Zinn M, Khatib O, Roth B, Salisbury JK (2002) Towards a human-centered intrinsically safe robotic manipulator. In: IARPIEEE/RAS joint workshop on technical challenges for dependable robots in human environments, Toulouse, France

58. Zinn M, Khatib O, Roth B (2004) A new actuation approach for human friendly robot design. In: 2004 IEEE international conference on robotics and automation. Proceedings. ICRA'04, vol 1, pp 249-254

59. Heinzmann J, Zelinsky A (1999) Building human-friendly robot systems. Int Symp Robot Res 305-312

60. Heinzmann J, Zelinsky A (2003) Quantitative safety guarantees for physical human-robot interaction. Int J Robot Res 22:479-504

61. Lew JY, Yung-Tsan J, Pasic H (2000) Interactive control of human/robot sharing same workspace. In: 2000 IEEE/RSJ international conference on intelligent robots and systems, 2000 (IROS 2000). Proceedings. pp 535-540

62. Zurada J, Wright AL, Graham JH (2001) A neuro-fuzzy approach for robot system safety. IEEE Trans Syst Man Cybern Part C Appl Rev 31:49-64

63. Traver VJ, del Pobil AP, Perez-Francisco M (2000) Making service robots human-safe. In: 2000 IEEE/RSJ international confer- ence on intelligent robots and systems (IROS 2000). Proceedings, vol 1, pp 696-701

64. Ikuta K, Ishii H, Nokata M (2003) Safety evaluation method of design and control for human-care robots. Int J Robot Res 22:281297

65. Haddadin S, Albu-Schaffer A, Hirzinger G (2007) Safe physical human-robot interaction: Measurements, analysis \& new insights. In: International symposium on robotics research (ISRR2007), Hiroshima, Japan

66. Kulic D, Croft E (2005) Anxiety detection during human-robot interaction. In: IEEE international conference on intelligent robots and systems, Edmonton, Canada, pp 389-394

67. Rani P, Sarkar N, Smith CA, Kirby LD (2004) Anxiety detecting robotic system-towards implicit human-robot collaboration. Robotica 22:85-95

68. Rani P, Sims J, Brackin R, Sarkar N (2002) Online stress detection using phychophysiological signals for implicit human-robot cooperation. Robotica 20:673-685

69. Inoue K, Nonaka S, Ujiie Y, Takubo T, Arai T (2005) Comparison of human psychology for real and virtual mobile manipulators. In: IEEE international conference on robot and human interactive communication, pp 73-78

70. Wada K, Shibata T, Saito T, Tanie K (2004) Effects of robotassisted activity for elderly people and nurses at a day service center. Proc IEEE 92:1780-1788

71. Koay KL, Walters ML, Dautenhahn K (2005) Methodological issues using a comfort level device in human-robot interactions. In: IEEE RO-MAN, pp 359-364

72. Sarkar N (2002) Psychophysiological control architecture for human-robot coordination-concepts and initial experiments. In: IEEE international conference on robotics and automation, Washington, DC, USA, pp 3719-3724

73. Nonaka S, Inoue K, Arai T, Mae Y (2004) Evaluation of human sense of security for coexisting robots using virtual reality. In: IEEE international conference on robotics and automation, New Orleans, LA, USA, pp 2770-2775

74. Kulic D, Croft E (2007) Physiological and subjective responses to articulated robot motion. Robotica 25:13-27

75. Kulic D, Croft E (2006) Estimating robot induced affective state using hidden Markov models. In: RO-MAN 2006-the 15th IEEE international symposium on robot and human interactive communication, Hatfield, pp 257-262

76. Kulic D, Croft EA (2007) Affective state estimation for humanrobot interaction. IEEE Robot Trans 23:991-1000

77. Kulic D, Croft E (2005) Safe planning for human-robot interaction. J Robot Syst 22:383-396

78. Khatib O (1986) Real-time obstacle avoidance for manipulators and mobile robots. Int J Robot Res 5:90-98 